\title{
Old and new adventures with fatty acids and their oxylipins: The road towards personalised clinical nutrition
}

\author{
Robert Gibson ${ }^{*}$,a \\ South Australian Health and Medical Research Institute (SAHMRI), and University of Adelaide, Adelaide, Australia
}

\begin{abstract}
After paying homage to the work of E. Chevreul, Prof. Robert Gibson went on in a lighthearted way to find similarities in the way they both approached their respective fields of research, as well as their way of life. Prof. Robert Gibson, who was awarded the 2021 Chevreul Medal, reported that "his huge delight was to witness the massive growth of lipid research and to have played a role in elucidating the role of dietary fats in the health of mothers and their babies". Prof. Gibson highlighted some of the major results he collected from Australian clinical studies conducted on the role of omega-3 fatty acids on the health outcomes of mothers and their infants. He first discussed the role of fish oil on visual acuity of babies and demonstrated that infant formulas supplying more than $1 \%$ of linolenic acid(ALA) seemed adequate to ensure optimal visual and cognitive development of term infants. However, in preterm infants, whether there is a specific need for DHA above the benefit provided by ALA, still needs to be clarified. He reported a small beneficial impact on the cognitive development of preterm infants receiving DHA enriched breast milk of their mothers ( $1 \%$ of total fatty acids). He then discussed data from his large randomised clinical trials conducted on pregnant women receiving a DHA dietary treatment $(800 \mathrm{mg} / \mathrm{d}$ DHA) or placebo, that suggested that DHA may decrease the risk of preterm birth (DOMInO trial, 2400 women). This effect was confirmed in the ORIP trial (5400 women) which found that preterm birth could be prevented by a DHA supplement treatment mainly in women with a singleton pregnancy who had a low omega-3 status in the first trimester. In the last part of his review, Robert Gibson described the use of a new low cost, rapid and efficient method to monitor changes in blood levels of omega-3 fatty acids with clinical outcomes: the Dried Blood Spots (DBS) technology. The validation of this technique has been demonstrated in large trials like N3RO and ORIP involving large cohorts of women, which could not have been obtained easily by classical analysis of lipids. He went on to point out that free fatty acids (generally not explored despite their importance in many metabolic disorders) and oxylipins, are both stable and easily identified when they are preserved in a dry state on a paper matrix (DBS), thus opening new fields of research. To conclude, the major impact of Prof. Robert Gibson's work was identifying and overcoming one of the causes of early preterm birth (omega-3 deficiency), developing a tool to rapidly assess omega-3 status (the DBS technique) that together is close to being implemented into the world health system.
\end{abstract}

Keywords: Michel Chevreul / fatty acid pathway / maternal-infant nutrition / preterm infant / omega-3 DHA / dried blood spot

\begin{abstract}
Résumé - Anciennes et nouvelles aventures des acides gras et leurs oxylipines : vers une nutrition clinique personnalisée. Après un hommage très documenté à E. Chevreul, le Prof. Robert Gibson a mis en lumière leurs similitudes concernant à la fois leur manière d'appréhender la science et leur mode de vie. Le Prof. Robert Gibson, qui venait d'être récompensé de la Médaille Chevreul 2021, a déclaré que son plus grand plaisir avait été d'être le témoin de l'immense progression de la recherche sur les lipides et d'avoir pu participer à l'élucidation du rôle des lipides alimentaires sur la santé des mères et de leurs nourrissons. Dans sa présentation, le Prof. Robert Gibson a rapporté les principaux résultats qu'il a recueillis à partir de ses études cliniques australiennes menées sur le rôle des acides gras oméga-3 concernant les paramètres de santé des mères et de leurs nourrissons. Il a d'abord identifié le rôle des huiles de poisson sur l'acuité visuelle des nourrissons et démontré que les formules infantiles apportant plus de $1 \%$ en d'acide linolénique (ALA)
\end{abstract}

\footnotetext{
*Correspondence: robert.gibson@adelaide.edu. au

${ }^{a}$ Present address: Robert A. Gibson, Professor Emeritus University of Adelaide, Principal Research Fellow SAHMRI, Adelaide, Australia.
} 
semblaient efficaces pour assurer un développement visuel et cognitif optimal des nourrissons nés à terme. En revanche, chez les prématurés, le besoin spécifique en DHA, en plus de l'apport en ALA restait à être clairement établi. Il a montré qu'il y avait un impact bénéfique modéré sur le développement cognitif des prématurés recevant un lait maternel enrichi en DHA (1\% des acides gras totaux). Enfin, le Prof. Robert Gibson a montré que ses résultats obtenus à partir des données issues de ses larges essais cliniques randomisés menés sur des femmes gestantes recevant un complément nutritionnel en DHA $(800 \mathrm{mg} / \mathrm{j})$ ou un placebo, que le DHA peut diminuer le risque de naissance prématurée (essai DOMInO, 2400 femmes). Cet effet a été confirmé par l'étude ORIP (5400 femmes) qui montre que la prématurité du nouveau-né pourrait être évitée par une supplémentation en DHA, principalement chez des femmes primipares présentant un faible statut en oméga-3 au cours du premier trimestre de leur grossesse. Dans la dernière partie de sa revue, le Prof. Robert Gibson a décrit l'utilisation d'une nouvelle méthode peu coûteuse, rapide et efficace pour suivre l'évolution des taux sanguins d'acides gras oméga-3 ayant un impact clinique: la technologie DBS (Dried Blood Spots). La validation de cette technique a déjà été établie à partir des résultats de larges études telles que N3RO et ORIP rapporté ci-dessus, impliquant des cohortes importantes de femmes, résultats qui n'auraient pu être obtenus facilement par les méthodes classiques d'analyses d'acides gras. Également, il a ainsi pu mettre en évidence que l'étude des acides gras libres (généralement peu explorés, bien que responsables spécifiquement de certains désordres métaboliques) et des oxylipines, qui sont stables et bien identifiés quand ils sont prélevés sur une matrice papier (DBS : Dried Blood Spots) va ouvrir de nouvelles perspectives très prometteuses en recherche. Pour conclure, l'impact majeur du travail du Prof. Robert Gibson a été d'identifier et de démontrer une des causes majeures de la prématurité (déficience en oméga-3) et de développer une technique nouvelle permettant d'évaluer rapidement ce statut en oméga-3 (technique DBS), ce qui globalement permet d'envisager une mise en œuvre prochaine dans le système mondial de santé.

Mots clés : Michel Chevreul / voie des acides gras / nutrition mère-enfant / enfant prématuré / oméga-3 DHA / tache de sang séché

Since1963, a "Chevreul medal" has been awarded each year to a distinguished researcher from France and overseas. This prize was given in honour of Michel Eugène Chevreul (Fig. 1) (31 August 1786-9 April 1889) who was a French chemist whose work with fats led to the discovery of margaric acid, and creatine (Wikipedia, 2021). He lived to 102 and was not only a pioneer in the field of fats but also gerontology and the arts. He is also one of the 72 people whose names are inscribed on the Eiffel Tower. Chevreul's scientific work covered a wide range, but he is best known for the classical research he carried out on animal fats, published in 1823 (Recherches sur les corps gras d'origine animale). This enabled him to elucidate the true nature of soap and to isolate stearic and oleic acids, the names of which he invented.

I wish I had known Chevreul as he was a determined enemy of charlatanism in every form, and a complete sceptic as to the "scientific" psychic research or spiritualism which had begun in his time. His research debunking the "magic pendulum", dowsing rods and table-turning was revolutionary. I wonder what he would have made of the spurious claims made by the nutraceutical industry and the fake news that floods the Internet today?

I have lived only $80 \%$ of Chevreul's lifetime but it has been my huge delight to witness the massive growth of lipid research and to have played a role in elucidating the role of dietary fats in the health of mothers and their babies. My greatest pleasure is to know that our work in identifying and overcoming one of the causes of early preterm birth (omega-3 deficiency) is close to being implemented into our health system. I would like to indulge the reader with a few examples of the experiments that have excited me over the years and that still offer challenges to the field.
What I discovered when reading about Chevreul was that he and I had similar ways of looking at our worlds. In 1861, Chevreul developed a circular (Fig. 2) chromatic diagram for the dye industry as a way to define and name the colours, that greatly facilitated the study of complementary colours and the modifications produced by their mutual proximity. One hundred and fifty years later, I proposed a circle of fatty acid synthesis to try to explain the (Fig. 3) implications of the Sprecher Shunt pathway in which the single delta- 6 desaturase was used twice in the conversion of 18 carbon essential fatty acids to 22 carbon homologues such as DHA (Gibson et al., 2013). When the pathway is laid out in this way, one is forced to the realisation that, at any one time, there are at least three 18 carbon and up to three 24 carbon fatty acids competing for access to the delta- 6 desaturase enzyme.

I used this diagram in an attempt to help me understand the implications of this double use of the delta- 6 desaturase enzyme and how the conversion of the plant-derived alphalinolenic acid(ALA, 18:3n-3) to the long-chain eicosapentaenoic acid (EPA, 20:5n-3) and docosahexaenoic acid (DHA, $22: 6 n-3)$ might be regulated by the level of polyunsaturated fatty acids (PUFA) in the diet. This resulted in my biggest animal experiment in which weanling rats were fed one of 54 different diets for three weeks. The diets varied in the percentage of energy (en\%) of LA(0.07-17.1 en\%) and ALA (0.02-12.1 en\%) (Fig. 4) by manipulating both the fat content and the balance of vegetable oils (Gibson et al., 2013). The results confirmed the hypotheses of circle diagram, namely that the peak of DHA accumulation in plasma phospholipids was attained following feeding a narrow dietary range of between 1-3 en\% ALA and 1-2 en\% LA (where competitive inhibition was least) but was suppressed to basal 


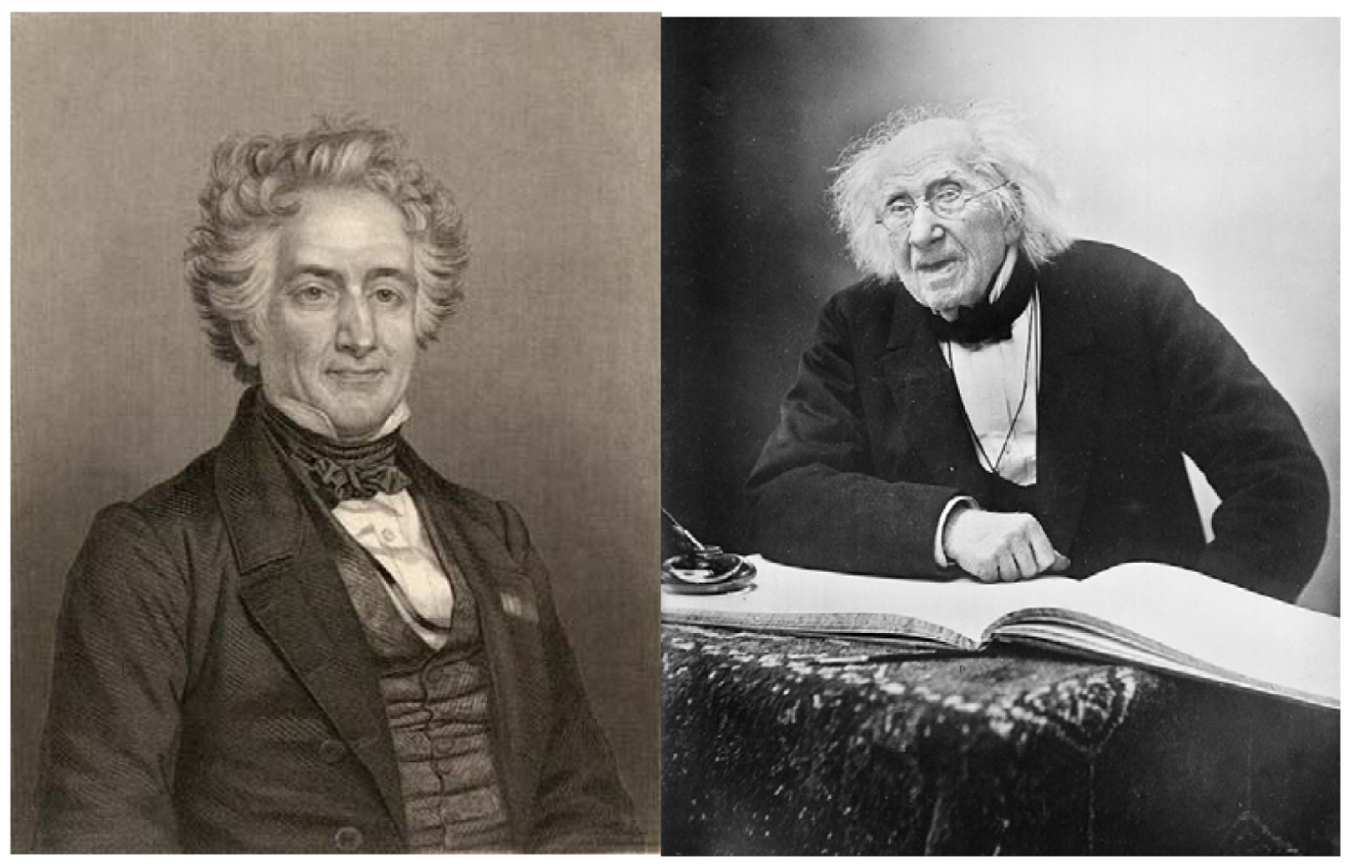

Fig. 1. Michel Eugène Chevreul over the years.

800. Chevreul's classification of colors, and chromatic diagram.-The chromatic diagram, of Cherreul, fig. 441, greatly

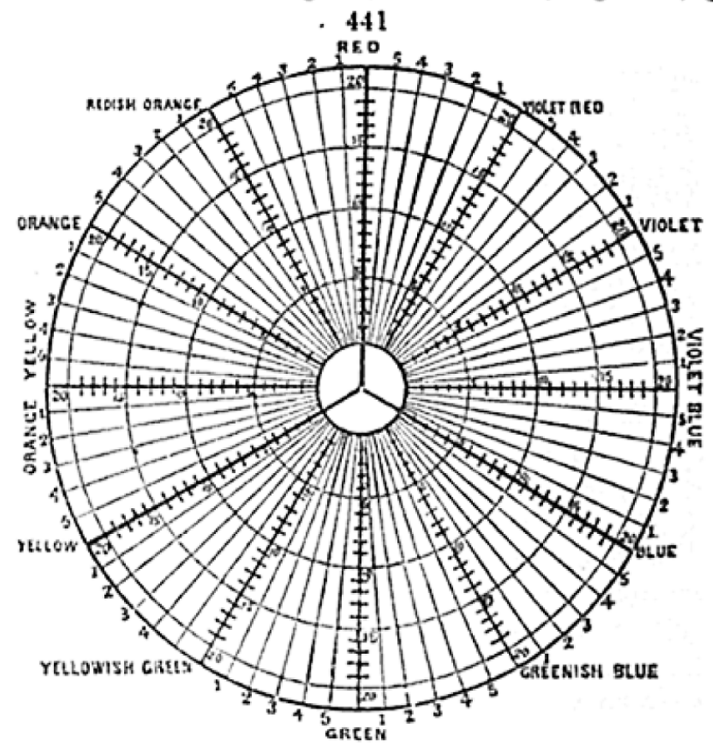

facilitates the study of cemplementary colors, and the modifications produced by their mutual proximity.

Fig. 2. Chevreul's circle of colour.

levels at dietary intakes of total polyunsaturated fatty acids (PUFA) above $3 \mathrm{en} \%$. We concluded that it is possible to enhance the DHA status of rats fed diets containing ALA as the only source of n-3 fatty acids but only when the level of dietary PUFA is low ( $<3$ en $\%$ ) (Gibson et al., 2013). The confirmation of our findings can be found in other studies including a seminal paper by Drs. Guesnet and Cunnane and

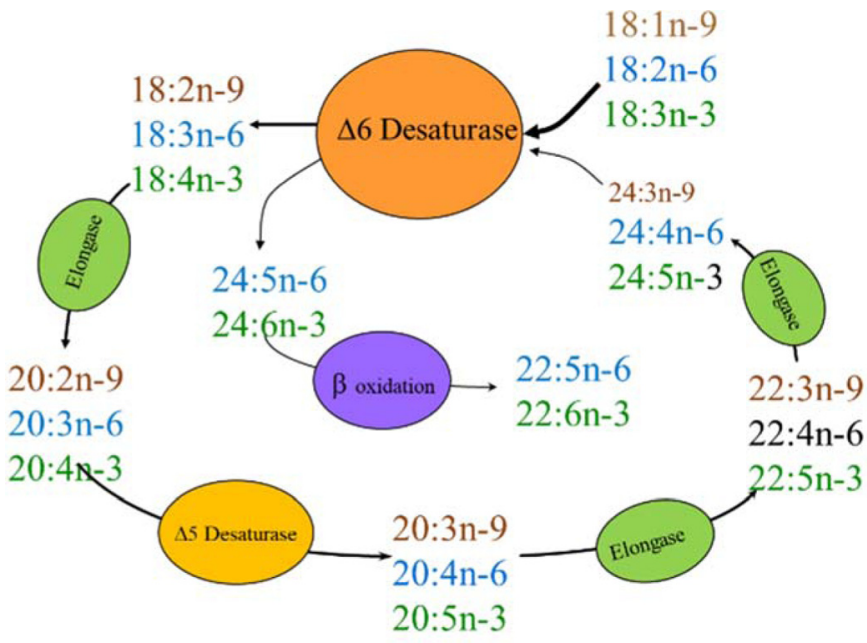

Fig. 3. Circle of fatty acid metabolism. Schematic pathway of conversion of 18 carbon essential fatty acids to 20 and 22 carbon polyunsaturated fatty acids via chain elongation and desaturation and finally beta-oxidation. The pathway is drawn in a circle to highlight the fact that there is only a single delta- 6 desaturase in mammalian systems that is utilised twice. This results in up to six fatty acids completing for access to the delta- 6 desaturase at any one time depending on dietary fat intake.

others (Plourde and Cunnane 2007; Guesnet et al., 2011). These principles have been confirmed by Delplanque and co-workers who showed that butter fat with low levels of PUFA can induce high levels of DHA in the brain in animals (Delplanque et al., 2013). Sadly, although similar data can be seen in human studies, learned bodies and industry continue to 


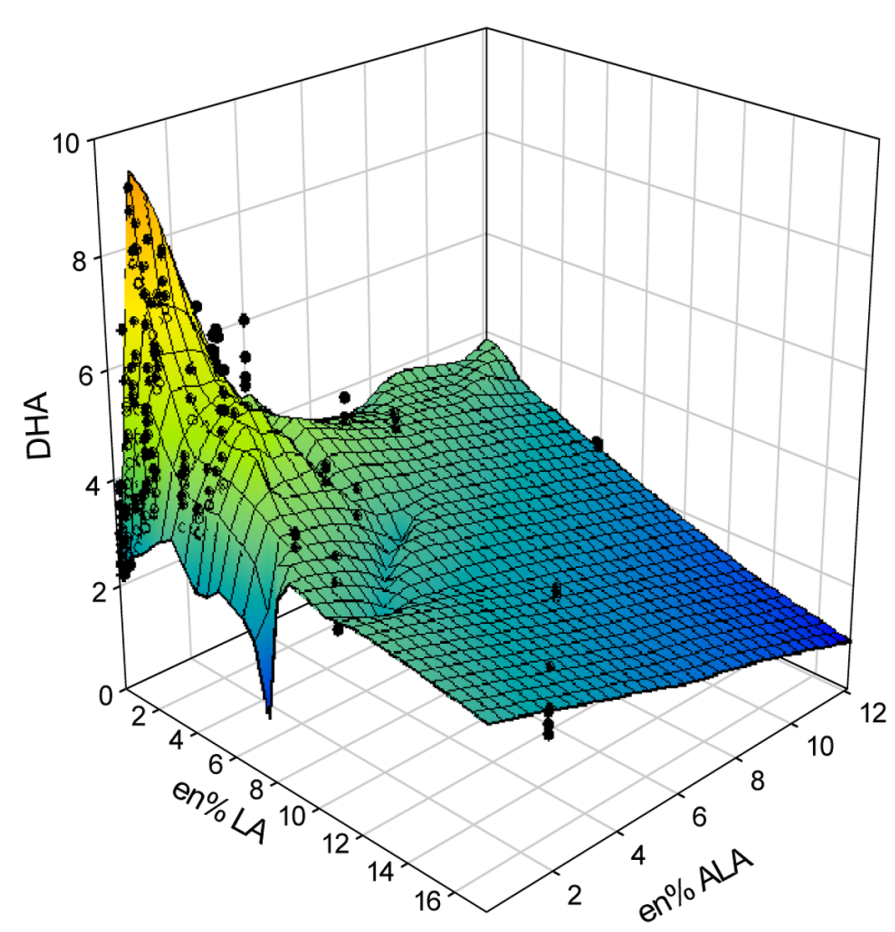

Fig. 4. Three-dimensional plot of plasma phospholipid DHA levels from rats fed a range of over 50 diets with varying levels of omega- 6 linoleic acid (LA) and omega-3 alpha linolenic acid (ALA) to assess the validity of the pathway shown in Figure 3. The peak of plasma phospholipid DHA was attained as a result of feeding a narrow dietary range of 1-3 en \% ALA and 1-2 en\% LA but was suppressed to basal levels at dietary intakes of total polyunsaturated fatty acids above 3 en $\%$. We concluded the data confirmed both the pathway and the utility of displaying it in a circular format. Individual raw data values are represented by black dots. Adapted from Gibson et al. (2013).

recommend diets that are high in PUFA rather than monounsaturated fatty acids. I have discussed this issue in a paper (Gibson, 2018) that summarised the ideas expressed in my ISSFAL Alexander Leaf Award in 2012.

Much of my work has been concerned with the role of dietary fats on the health outcomes of mothers and their babies. My explorations into the role of omega- 3 fatty acids in the neurodevelopment of infants truly began in the mid 1990's with a study initiated by my newly arrived graduate student Maria Makrides and was spurred by the early work of Martha Neuringer who demonstrated visual loss in omega-3 fatty acid deficient infant rhesus monkeys (Neuringer et al., 1984). We investigated whether the disparity in neural maturation between breastfed and formula-fed term infants could be corrected by the addition of docosahexaenoic acid(DHA) (Fig. 5), to infant formula. Healthy term infants were randomised at birth to receive either an omega-3 supplemented or control formula if their mothers had chosen to bottle-feed. Breastfed term infants were enrolled as a reference group. Infant erythrocyte fatty acids, anthropometry and visual evoked potential (VEP) acuity were assessed as a marker of neurodevelopment. VEP acuities of breastfed and supplemented-formula-fed infants were better than those of control-formula-fed infants at both 16 and 30 weeks of age (Makrides et al., 1995). Erythrocyte DHA in breastfed and supplemented-formula-fed infants was maintained near birth levels throughout the 30-week study period but fell in controlformula-fed infants. Erythrocyte DHA was the only fatty acid that consistently correlated with VEP acuity in all infants at both ages tested. We concluded that a continuous supply of DHA might be required to achieve optimum VEP acuity in infants receiving the formulas of that era, with a level of ALA below $1 \%$ en.

At that time, it seemed that it would be "full steam ahead" and that the field would rapidly be able to define the omega-3 requirements for term and preterm infants. We expanded our term infant studies to make them larger and monitored more complex measures of neurodevelopment including the Bayley test. We soon learned that research rarely follows a straight line so that studies by others appeared to show benefit (Birch et al., 2010) while ours consistently failed to show differences between children-fed-standard-infant formula and those receiving long chain PUFA enhanced formula. What we didn't quite notice at the time was that the level of ALA in most infant formulas had quietly increased ALA levels to closer to $2 \%$ en. We have recently re-examined the literature and our conclusion is provided that formulas are ALA-adequate ( $>1 \%$ en), no additional omega-3 LCPUFA are required (Collins et al., 2019). Concomitant with term infant studies, we also hypothesised that infants born preterm would be particularly sensitive to nutritional deficiencies and we conducted several studies following which we concluded that the need for omega-3 LCPUFA in addition to the amount of ALA was not clear but if there was any benefit, it was small (Collins et al., 2019).

We also hypothesised that infants born preterm would be particularly sensitive to nutritional deficiencies. So, we began a trial called DINO that involved 650 infants born less than 33 weeks gestation. The infants received breast milk expressed from their mothers who had been supplemented with either tuna oil (Fig. 6) or control oil resulting in infants receiving milk containing either $1 \%$ DHA or $0.3 \%$ DHA. Infants were tested at 18 months using Bayley Mental Development Index and all the way out to 7 years when they were tested for full scale IQ (Collins et al., 2015). While differences were seen in subsets at 18 months, all differences had disappeared by 7 years of age probably due to long-term environmental impact. We concluded that the need by preterm infants for marine-type omega- 3 in addition to the amount of adequate ALA was not clear, but if there was any benefit, it was small.

By 2010, we had developed a high level of skill in the design and conduct of randomised controlled trials. In particular, we had developed strong collaborations with outstanding clinicians and statisticians that strengthened our capabilities. We had become aware of the seriousness of bronchopulmonary dysplasia (BPD), a major cause of mortality and long-term respiratory and neurological morbidity in very preterm infants. We also had secondary evidence from our DINO trial that DHA could help in the prevention of this chronic lung disease (Fig. 7).

We therefore undertook a large multicentre, randomised controlled trial in which we randomised over 1200 infants born less than 29 weeks' gestation, from 13 centres in Australia, New Zealand and Singapore (Collins et al., 2017). Infants received an enteral emulsion containing DHA $(60 \mathrm{mg} / \mathrm{kg} /$ day $)$ or a control emulsion without DHA. Sadly, the rate of BPD was 

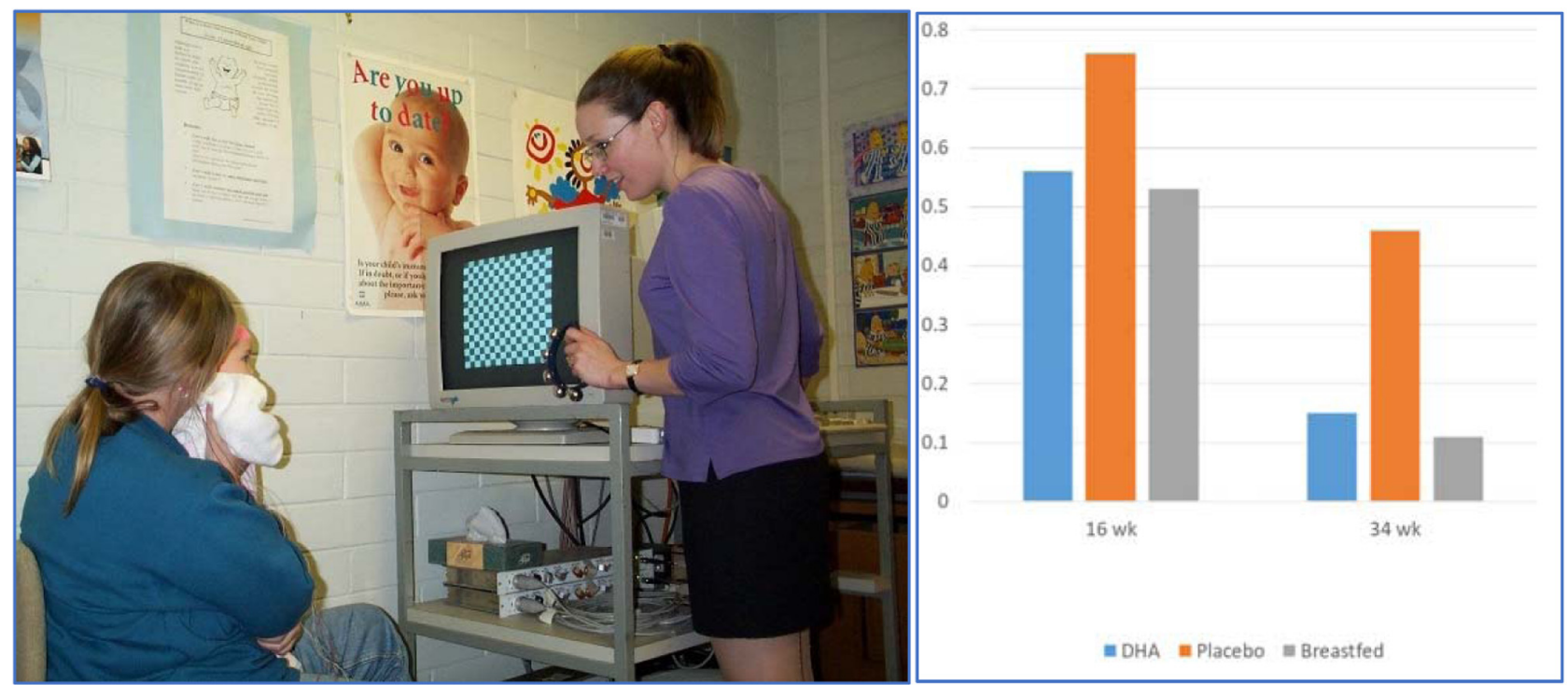

Fig. 5. Measurement of visual acuity in term infants (left). VEP acuities of breastfed and supplemented-formula-fed infants were better than those of control-formula fed infants at both 16 and 30 weeks of age (Makrides et al., 1995). The data from this study provided the first clue that infant formulas of that period were deficient in omega-3.

\section{Our attempt to resolve the issue: DHA to Improve Neurodevelopmental Outcomes of preterm infants (DINO) \\ - $P=$ Infants born $<33$ weeks' gestation, $n=657$

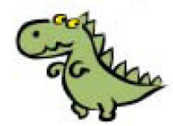 \\ - I = High-DHA feeding practice ( $\approx 1 \%$ total fat) \\ - Breast milk: Mothers - 6x500mg tuna oil capsules/day \\ - $\mathrm{C}=$ Standard feeding practice $(\approx 0.3 \%$ total fat $)$ \\ - Breast milk: Mothers - 6x500mg soy oil capsules/day \\ - $\mathrm{O}=$ Neurodevelopmental outcome \\ - Bayley Mental Development Index (MDI) at 18 months' corrected \\ - Full Scale IQ of the Wechsler Abbreviated Scale of Intelligence (WASI) at 7 years}

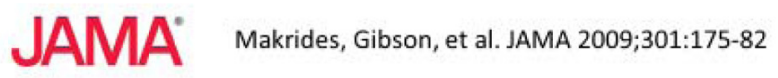

Fig. 6. DINO involved 650 infants born less than 33 weeks gestation. The infants received breast milk expressed from their mothers who had been supplemented with either tuna oil or control oil resulting in infants receiving milk containing either 1\% DHA or $0.3 \%$ DHA MDI scores overall at 18 months did not improve and at 7 years there was no difference between groups overall or in any subgroups.

actually higher in the DHA group than in the control group. This effect was confirmed by the Canadian Moby Dick trial (Marc et al., 2020). This trial taught us some valuable lessons including that if you want the correct answer, one needs to ensure that your trial is large enough to give you the statistical power to determine whether your result is true or not. It was also a timely reminder that all nutrients have optimal intake ranges beyond which people can experience either a deficiency or a toxicity. This may be critically true in the case of vulnerable preterm infants.
We were convinced that if effects of omega-3 fatty acids were to be seen in infants, they may best be revealed through supplementation trials with pregnant women. We embarked on a trial called DOMInO that involved randomising 2400 women into treatment $(800 \mathrm{mg} / \mathrm{d} \mathrm{DHA})$ or placebo that primarily was designed to test whether DHA could reduce the rate of postnatal depression or benefit the neurodevelopment of the children at 4 or 7 years (Makrides et al., 2014; Gould et al., 2017). The statistical power we had with such a large number meant that when the results emerged (null) we, and JAMA, 


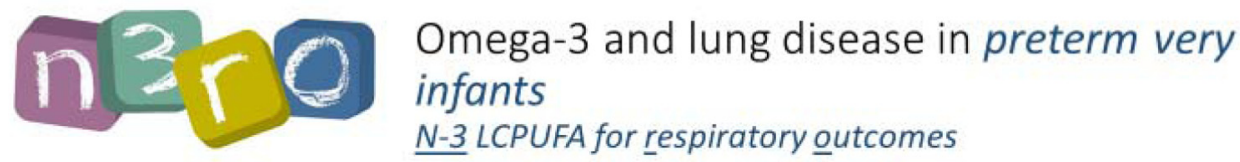

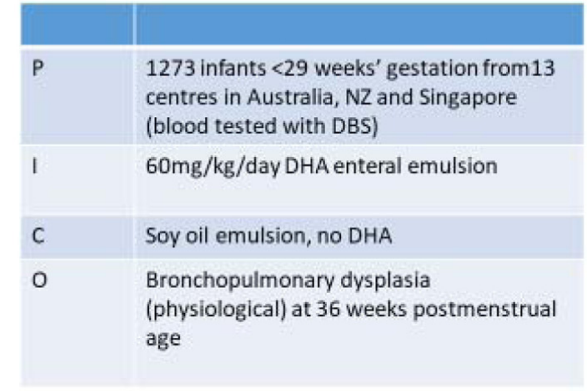

Adj* Rel Risk (95\% Cl) Adj P-value

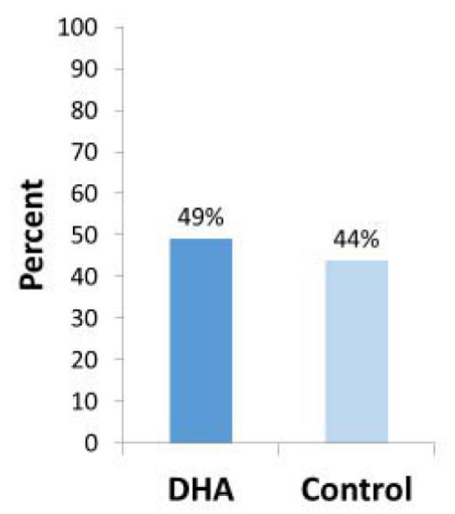

Collins, Makrides, McPhee et al, NEJM 2017;376:1245-55

Fig. 7. The N3RO trial involving infants born less than 29 weeks' gestation. Infants received an enteral emulsion containing DHA or a control emulsion without DHA. We were stunned to discover that the rate of BPD was actually higher in the DHA group than in the control group.

were happy to reject our hypothesis and we are thus sure that DHA could not prevent postnatal depression or improve cognitive and language development in their offspring during early childhood.

However, the data we obtained from DOMInO did suggest that DHA may decrease the risk of early preterm ( $<34$ weeks) and preterm $(<37$ weeks) birth. These data enabled us to get funding from our government to support the ORIP trial in which we enrolled 5400 women who were randomised to a DHA treatment similar to DOMInO or control (Makrides et al., 2019b) (Fig. 8). Imagine our shock when we broke the code and discovered that the result was null-no effect of supplementation. After all that work, a null result! However, subsequent analyses showed that when the women with multiple pregnancies were deleted from the analyses, it was obvious that singleton women with low omega-3 status at baseline were more likely to suffer an early preterm birth and further, if we treated those mothers (Fig. 9) with DHA, their risk of early preterm birth was decreased. Curiously, although women with higher total omega-3 status at baseline were at lower risk of early preterm birth, adding omega-3 supplementation to these women may increase their risk. Most importantly, because we were able to measure the whole blood fatty acid status of all the women at baseline and again at 34 weeks gestation, we were able to calculate cut-points for omega-3 fatty acids that were indicative of risk for depletion and sufficiency (Simmonds et al., 2020).

These results confirm the power in the simple process of assessing fatty acid status. While nutrient status can best be determined by assaying levels in blood, the collection, storage, and transport of blood samples by pathology services have changed little in the last 50 years. Although changes are coming, a visit to the doctor can still require a subsequent visit to a pathology laboratory for collection of a blood sample
(5-20 mL) via venipuncture that in turn must be transported under refrigeration to a laboratory, centrifuged and processed/ stored under controlled conditions. Long-term storage requires ultra-cold facilities. All these facilities are difficult to find in remote communities in large countries like Australia.

The need for remote sampling of blood samples and delivery to a central processing laboratory for our national and international clinical trials forced us to examine the use of dried blood spot technology. Dried blood spots obtained by pricking the heel or finger and collecting onto filter paper has been around since 1963 when it was reported by Robert Guthrie (Guthrie and Susi, 1963) and used to screen for metabolic diseases in large populations of neonates. It remains standard practice in most countries today and uses a standardised filter paper (similar to Whatman 903). Using similar, Franca Marangoni and Claudio Galli published a method for the collection and preservation of blood drops (Marangoni et al., 2004) and reported similar fatty acid patterns to blood extracted and derivatised in the traditional way. They claimed that the fatty acids in the DBS were stable for long periods and the test was sensitive enough to detect changes in dietary fat consumption (Marangoni et al., 2007). Similar systems have been widely used by commercial testing laboratories.

We have explored a range of parameters that might affect the accuracy of DBS in the estimation of fatty acid spectrum seen in whole blood. The quality of paper can be important with saturated fatty acids detectable in many papers that can influence results particularly when the amount of blood spotted on papers is small (Liu et al., 2014). We have determined that appropriate levels of antioxidants such as BHT can help preserve blood fatty acids for longer periods at room temperature. One method (Fig. 10) that our University patented made use of paper impregnated with silica gel (for 


\section{The ORIP trial: Inspired by the results of the DOMInO trial: ㅇmega-3 LCPUFA to Reduce}

the Incidence of Prematurity
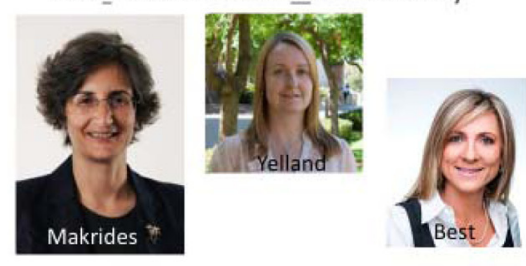

- Multicentre, parallel group,

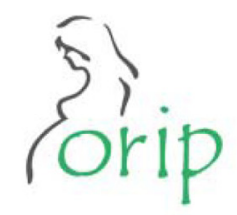
blinded RCT in 6 centres

- Supplementation from <20 weeks' until 34 weeks' gestation to reduce incidence of early preterm birth

- 5544 women with singleton or twin pregnancies

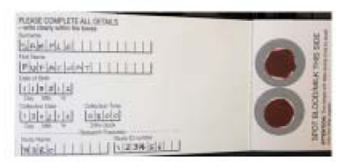

- >2.5 million capsules donated by Croda and Efamol

- Fatty acid profiles at entry and 34 weeks'

Fig. 8. The ORIP trial was the largest study of its type involving over 5500 women with singleton or twin pregnancies. The measurement of whole blood fatty acid levels at two time points allowed us to not only assess compliance but also to determine risk factors for early preterm birth.

\section{Effect of supplementation: Relative risk of early preterm birth by baseline omega-3 status in ORIP singleton pregnancies:}

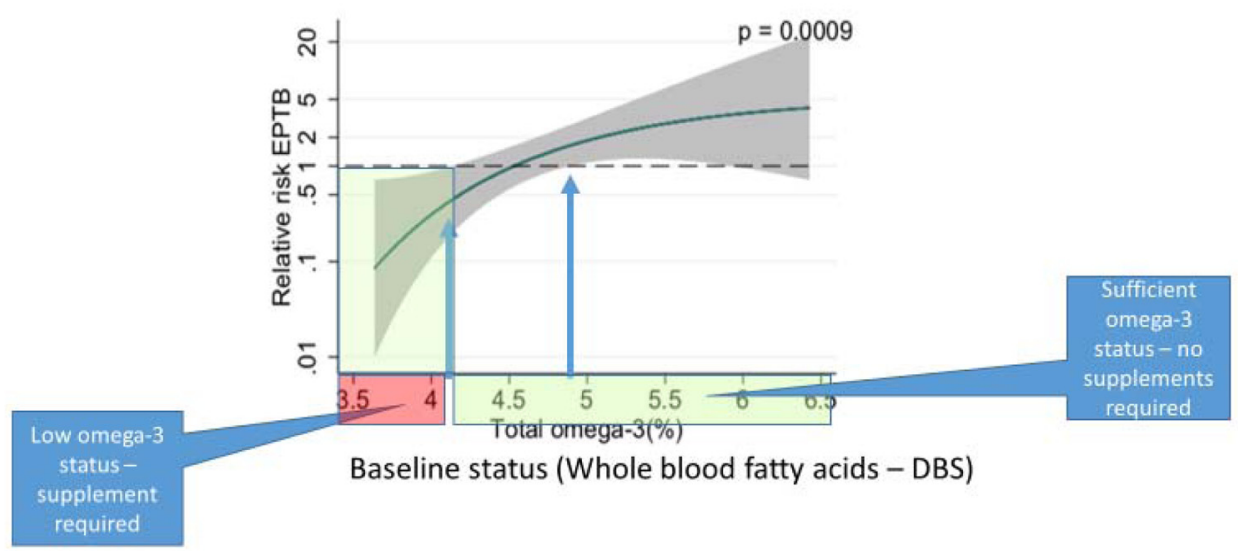

Fig. 9. Relative risk of early preterm birth as related to total omega-3 fatty acids in whole blood (Simmonds et al., 2020). We were able to calculate cut-points for omega-3 fatty acids that were indicative of risk for depletion and sufficiency. In women with a total omega-3 status $\leq 4.1 \%$ of total fatty acids, omega-3 supplementation substantially reduced the risk of early preterm birth compared with control. Conversely, supplementing women with a baseline status above $4.9 \%$ increased early preterm birth. This highlights the need for accurate assessment on omega-3 status early in pregnancy.

added polarity), and was treated with chelating agent (EDTA) to bind Fe ions plus an antioxidant (Liu et al., 2014). We demonstrated that such a system could preserve the fatty acids in blood for at least 2 months at room temperature and for over two years when stored at $-15^{\circ} \mathrm{C}$.

There have been many DBS systems reported that measure a variety of nutrients and chemical compounds (Drolet et al., 2017) although some require cold-chain which to me, defeats the true purpose of the system. To be effective, a DBS system either needs to protect the compounds in question or allow breakdown of the target to a stable derivative (Fig. 11).
Regardless of DBS type, there are key features of DBS systems that are important to consider. First and foremost is the fact that the biological sample, when applied to the paper, is dry. In most cases, this means that enzymatic breakdown is prevented as most proteins are inactive in this state. Importantly, because the materials on the DBS are free of water, extraction rarely needs to involve liquid:liquid extraction of the Folch type. Thus, the lipid soluble materials in DBS can be extracted by simply washing with organic solvents and water-soluble compounds can be directly eluted with water or polar solvents. In addition, many compounds can be directly derivatised by 


\section{Development of our DBS system}

- Some collection papers contain contaminant fatty acids (16:0, 18:0)

- So do other materials like latex rubber gloves - Nitrile are OK

- Fingers (skin) contain a range of fatty acids

-We tested a range of papers and treatments and settled on:

- Silica gel impregnated paper for extra polarity

- A chelating agent (EDTA) to bind the iron in blood cells

- An antioxidant (BHT) - but a range were tested

- Achieved stability of LCPUFA of $>90 \%$ over 2 months at room temp

- Stable for over 2 years when kept in freezer $(-150 \mathrm{C})$

Fig. 10. Collecting whole blood spotted on filter paper and dried (DBS) to preserve, transport and store fatty acids.

Significance of DBS: It's DRY

- "DRY" technology

- Allows direct extraction with either aqueous or organic solvents

- By-passes cold chain dependency

- Transport can be via postal service

- Eliminates:

- Enzymatic activity during storage and transport

- Need for freezing during storage and transport

- Need for liquid/liquid extraction

- Reduces time to instrument analysis - analytes can be eluted directly off matrix

Fig. 11. Advantages of dried blood spot technology for the collection, transport and storage of whole blood samples.

adding reagents directly to the DBS paper. We have also used the basic DBS system to transfer samples between labs and for long-term storage. An important advantage for our international clinical trials is that biological samples dried on paper allows transport across international borders via the postal system.

There is no doubt that there are some limitations to DBS systems. Paper is inherently impure and even low levels of impurities can influence results, particularly when the test is sensitive and based on LCMS. However, numerous synthetic matrices are now on the market and these deserve to be investigated. Many DBS systems are not volumetric by nature and the amount of biological fluid on DBS cards is often estimated by the area of the spot or the area of the disc sampled. These deficits can be overcomed by applying known volumes to the cards and then harvesting the entire spot for analysis.

Probably the best-known example of the use of the DBS cards for fatty acid analyses is the Omega-3 Index defined by Harris and co-workers (Harris et al., 2017; Farrell et al., 2020). Defined as the percentage of EPA+DHA in erythrocytes, the Omega-3 Index has been widely used to estimate risk of death from cardiovascular disease. In point of fact, erythrocytes are only rarely separated from plasma and directly measured for
LCPUFA profile. Instead, it is increasingly common for whole blood samples to be collected on coated paper. The fatty acid composition of the whole blood is subsequently determined and mathematical equations used to estimate the level of EPA+DHA in erythrocytes, resulting in fewer steps than directly measuring the fatty acid composition in red cells isolated from blood. More recently, we have devised the Omega-3 Pregnancy Score that is a simple summation of all omega-3 fatty acids detected in a DBS sample that is linked to prematurity (Simmonds et al., 2020).

We have found that DBS systems are particularly useful in our clinical trials to monitor adherence where we have treated with omega-3 fats (Collins et al., 2017; Makrides et al., 2019a). In the largest of these trials ORIP, we were able to establish that among women with singleton pregnancy $(\sim 5000)$, those women who had a total omega-3 level of less than $4.2 \%$ of total fatty acids at baseline (about 13 weeks gestation) benefitted (reduced early preterm births) from treatment while those who had levels of omega-3 fatty acids above $4.9 \%$ were already at low risk of early preterm birth and further supplementation may increase their risk of early birth (Simmonds et al., 2020). These results highlighted the usefulness of DBS systems to not only monitor the effects 


\section{Dietary PUFA: incorporation and metabolism}

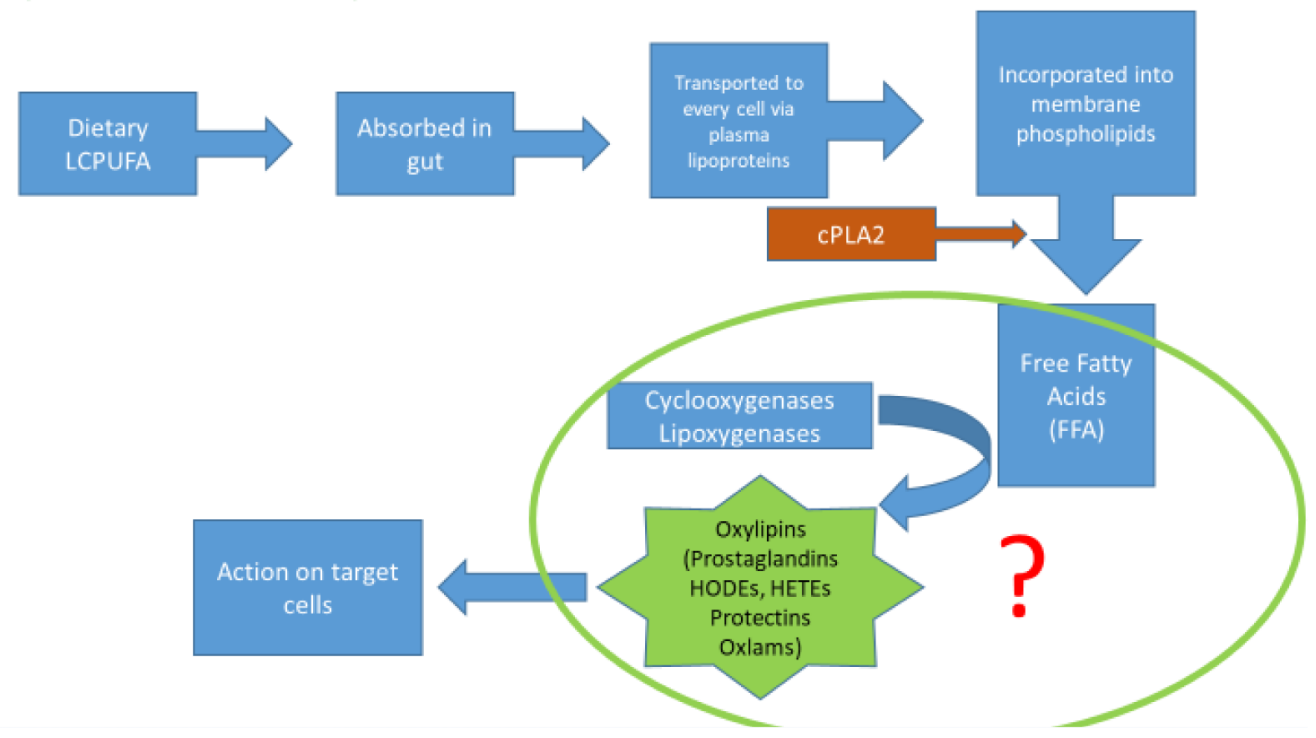

Fig. 12. Diagram to explain how LCPUFA influence the metabolism of cells in order to elicit clinical effects.

of dietary intervention on fatty acid status but also as a tool for predicting clinical outcomes.

Traditional methods of assessing fatty acid status, do not address the mechanism by which fatty acids are thought to work. Some of the biological effects of dietary fatty acids are mediated by downstream lipid derivatives (collectively known as oxylipins (Fig. 12)), their properties depending on the parent fatty acid from which they are derived (Gabbs et al., 2015). Release of FFA is normally low unless PLA2 is induced by trauma or infection where localised inflammation may occur. People with chronic illnesses often have higher levels of FFA where they are involved in modulation of the production of cytokines and chemokines, expression of adhesion molecules as well as the release of pro- and anti-inflammatory mediators including oxylipins. There is increasing evidence that the level of FFA reflect poorly regulated immune-mediated diseases. For example, rheumatoid arthritis patients have altered levels of specific FFA relative to control subjects, most notably reduced levels of the omega-3 LCPUFA, EPA and DHA, and these FFA perturbations were associated with clinical features (Rodriguez-Carrio et al., 2016). In a similar way, it has been reported that patients with acute coronary syndrome have high levels of serum FFA with higher coronary artery disease scores (Ma et al., 2016).

A surprising result from our DBS studies has been the fact that not only were the esterified fatty acids stable on DBS over time but it was also possible to detect both free unsaturated fatty acids and their oxygenated derivatives, the oxylipins. We showed that FFA and a range of oxylipins could be stabilised for at least one month at room temperature and that their responses were linear over a biologically important range (Hewawasam et al., 2017, 2018). This tool has proven (Fig. 13) to be useful in international studies. We examined differences in Japanese term infants fed breast milk or mixed feeds and although esterified DHA levels were not different, levels of free DHA differed and were matched by changes in DHA-derived oxylipins.
We have also used this tool to measure the concentration of most total and free polyunsaturated fatty acids and their associated oxylipins over the course of pregnancy in the ORIP trial (Fig. 14) (Best et al., 2020). Our data suggest a differential response with or without omega-3 supplementation for DHA and DHA-derived oxylipins, which may have an important role to play in modulating pregnancy duration. The clinical significance of these changes continues to be explored, but it is obvious that dried blood spot systems have the capacity to detect changes in fatty acid and oxylipin status using only minute volumes of blood.

What these data suggest to me is a number of important issues. Dietary changes do not always result in equal changes in the fatty acids in all lipid fractions in blood. This is very apparent in the case of preterm infants who are receiving most of the lipids intravenously. There is no consistent relationship between the level of some LCPUFA in the total lipids in blood and the amounts of LCPUFA existing as FFA. For example, we could not detect changes in AA levels in preterm infant blood total lipids but there were clear differences in AA-FFA level. Finally, the levels of oxylipins from any of the LCPUFA were more related to FFA levels that the levels seen in the total blood lipids. These data suggest that the flow of fatty acids from the diet that will ultimately translate into a change in a physiological or clinical outcome follows the pathway outlined in the figure.

The utility of DBS is clear, provided that the metabolite in question can be made stable for the period of storage and transport. More work need to be done if the true value of DBS technology is to be realised as clinical tool. DBS is at best good general tool that can yield results that are indicative but may lack the precision of many liquid-based pathology assays. For example, most DBS systems are not volumetric. Estimates of the volume of blood can be made by excising a known area of paper and equating that to the volume of blood. We have done this in our studies (Hewawasam et al., 2017, 2018) but there 


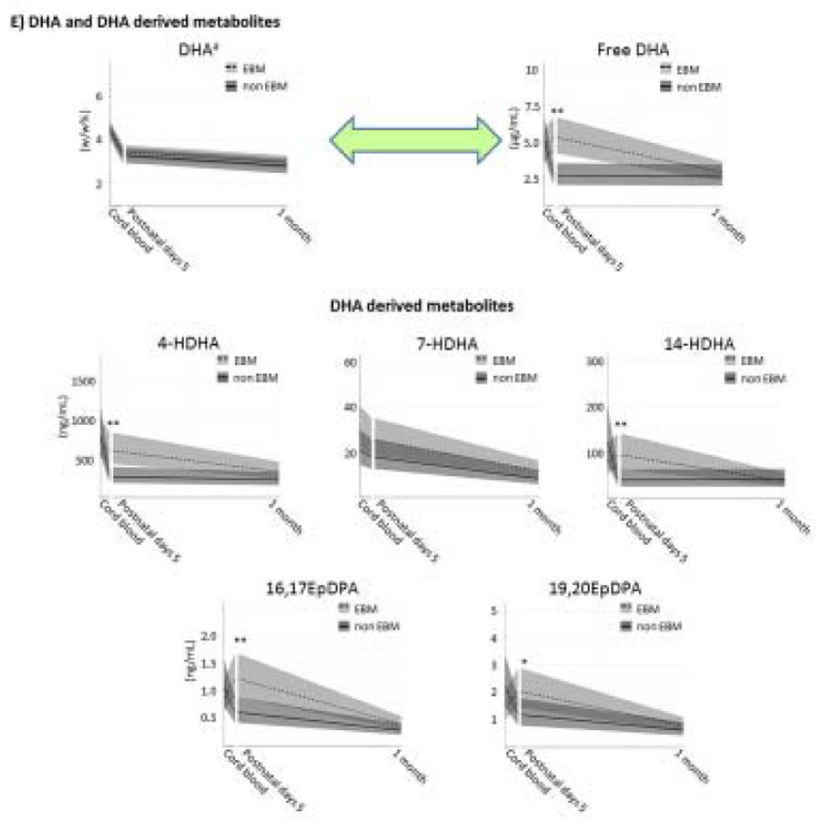

\section{Sensitivity: Whole blood lipid analysis of term infants fed breast milk or mixed feeds}

- No changes in esterified DHA levels

- Higher levels of free DHA in breast-fed (EBM) group

- Matched by changes in most DHA derived oxylipins

Fig. 13. Levels of esterified DHA, free DHA and DHA-derived oxylipins in Japanese term infants fed breast milk or mixed feeds.

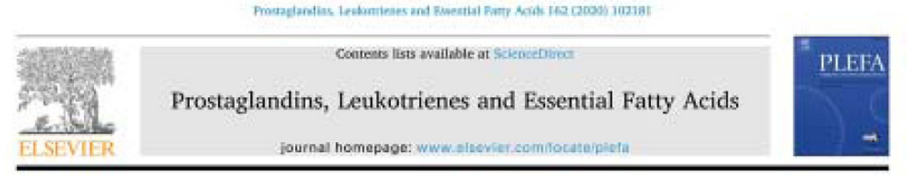

Effect of omega-3 lcpufa supplementation on maternal fatty acid and oxylipin concentrations during pregnancy

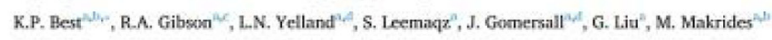

Sensitivity in the clinical

trial world - ORIP:

Changes in DHA and associated oxylipins

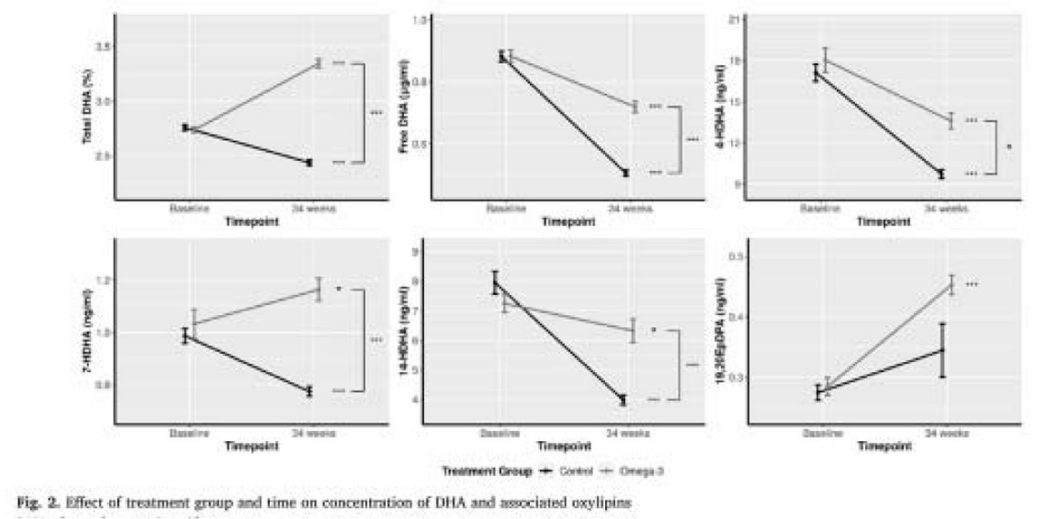

Fig. 14. Changes in levels total and free DHA and associated oxylipins over the course of pregnancy in the ORIP trial.

are now a variety of systems available for the collections of known volumes of blood that will allow results of nutritional assays to be expressed in molar terms. As fatty acids are commonly expressed as percentages, volumes are not an issue.

I believe that the potential of DBS systems has barely been addressed and in many ways most systems are little different to that developed by Guthrie sixty years ago. There is tremendous scope for the development of new matrices for blood collection. Paper is a complex material derived from plants and contains numerous compounds that can show up in analyses on GC and particularly on mass spectroscopy. Synthetic matrices have been reported (Ding et al., 2018). Perhaps consideration needs to be given to developing matrices specific to need the needs of protecting specific classes of compounds. We made use of the strong binding characteristics of silica gel and the chelating potential of EDTA (Liu et al., 2014), however, the possibilities of developing synthetic matrices with specific binding/chelating, protecting 


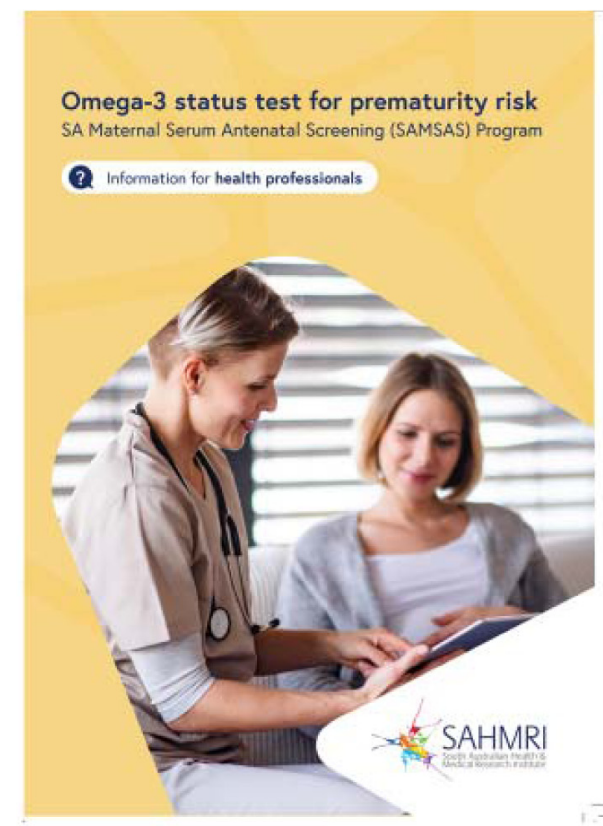

\section{Implementation in the State of South Australia: Omega-3 to reduce early preterm birth}

- About 15,000 births/year

- Screen serum total omega-3 fatty acids

- Use total omega-3 cut points from ORIP

- Targeted Approach

- Optimise those to treat

- Minimise risk and resources use

Fig. 15. Our new implementation study is designed to test the efficacy of a screen-and-treat approach to help reduce early preterm birth in the community.

properties seem to be endless. One can even conceive of agents applied to a matrix that allows derivatisation of specific compounds in situ.

In conclusion, DBS technology provides a useful tool for the screening of fatty acid levels in the blood of subjects in clinical trials or in large population studies. DBS is a useful low-cost tool that allows analytical labs to bypass cold-chain transport and storage but is also in need of improvements to realise its potential. Any tool that improves the ability of the investigator to relate fatty acid status with clinical outcome is welcomed by all. Importantly, it is only through well-designed, well-powered and well-conducted clinical trials that we are going to be able to unlock the roles of dietary fatty acids in health and disease (Fig. 15).

In Adelaide, we are about to see the fruition of our many years of work and the results of our ORIP trial and our systematic review of the field, translated into the community. We have just begun an implementation study in which all pregnant women in the State of South Australia (15000) will be tested for serum fatty acid status and if found to be low, will be offered capsules of vegan oil containing omega-3 LCPUFA, mainly as DHA. Our hope is that if successful in decreasing the rate of early preterm birth, we can see change in clinical practice worldwide.

There is little doubt that the field has evolved and I believe that we are closer to defining clinical roles for PUFA and in particular omega-3 fatty acids. However, I would like to point out that mechanisms of action of omega- 3 fatty acids are generally putative or lacking except in the case of the retina (Wheeler et al., 1975). This offers amazing opportunities for research and I am delighted to think that I played a small part.

Acknowledgement. This has been an enormous privilege and adventure and I thank the Société Française pour l'Étude des
Lipides for their award and I honour Michel Chevreul for his inspiration.

Merci beaucoup, je suis honoré. Un grand merci.

\section{References}

Best KP, Gibson RA, Yelland LN, et al. 2020. Effect of omega-3 lcpufa supplementation on maternal fatty acid and oxylipin concentrations during pregnancy. Prostaglandins Leukot Essent Fatty Acids 162: 102181.

Birch EE, Carlson S, Hoffman DR, et al. 2010. The DIAMOND (DHA Intake And Measurement Of Neural Development) study: A double-masked, randomized controlled clinical trial of the maturation of infant visual acuity as a function of the dietary level of docosahexaenoic acid. Am J Clin Nutr 91: 848-59.

Collins CT, Gibson RA, Anderson PJ, et al. 2015. Neurodevelopmental outcomes at 7 years' corrected age in preterm infants who were fed high-dose docosahexaenoic acid to term equivalent: A follow-up of a randomised controlled trial. BMJ Open 5: e007314.

Collins CT, Makrides M, McPhee AJ, et al. 2017. Docosahexaenoic acid and bronchopulmonary dysplasia in preterm infants. $N$ Engl $J$ Med 376: 1245-55.

Collins CT, Gibson RA, McPhee AJ, Makrides M. 2019. The role of long chain polyunsaturated fatty acids in perinatal nutrition. Semin Perinatol 43: 151156.

Delplanque B, Du Q, Agnani G, Le Ruyet P, Martin JC. 2013. A dairy fat matrix providing alpha-linolenic acid (ALA) is better than a vegetable fat mixture to increase brain DHA accretion in young rats. Prostaglandins Leukot Essent Fatty Acids 88: 115-20.

Ding X, Yang J, Dong Y. 2018. Advancements in the preparation of high-performance liquid chromatographic organic polymer monoliths for the separation of small-molecule drugs. J Pharm Anal 8: 75-85. 
Drolet J, Tolstikov V, Williams BA, et al. 2017. Metabolomics assessment of human dried blood spots and urine strips. Metabolites 7: 35-49.

Farrell SW, DeFina LF, Tintle N, et al. 2020. Higher omega-3 index is associated with more rapid heart rate recovery in healthy men and women. Prostaglandins Leukot Essent Fatty Acids 163: 102206.

Gabbs M, Leng S, Devassy JG, Monirujjaman M, Aukema HM. 2015. Advances in our understanding of oxylipins derived from dietary PUFAs. Adv Nutr 6: 513-40.

Gibson RA. 2018. Musings about the role dietary fats after 40 years of fatty acid research. Prostaglandins Leukot Essent Fatty Acids 131: 1-5.

Gibson RA, Neumann MA, Lien EL, Boyd KA, Tu WC. 2013. Docosahexaenoic acid synthesis from alpha-linolenic acid is inhibited by diets high in polyunsaturated fatty acids. Prostaglandins Leukot Essent Fatty Acids 88: 139-46.

Gould JF, Treyvaud K, Yelland LN, et al. 2017. Seven-year follow-up of children born to women in a randomized trial of prenatal DHA supplementation. JAMA 317: 1173-75.

Guesnet P, Lallemand SM, Alessandri JM, Jouin M, Cunnane SC. 2011. Alpha-linolenate reduces the dietary requirement for linoleate in the growing rat. Prostaglandins Leukot Essent Fatty Acids 85: 353-60.

Guthrie R, Susi A. 1963. A simple phenylalanine method for detecting phenylketonuria in large populations of newborn infants. Pediatrics 32: 338-43.

Harris WS, Del Gobbo L, Tintle NL. 2017. The Omega-3 Index and relative risk for coronary heart disease mortality: Estimation from 10 cohort studies. Atherosclerosis 262: 51-54.

Hewawasam E, Liu G, Jeffery DW, Muhlhausler BS, Gibson RA. 2017. A validated method for analyzing polyunsaturated free fatty acids from dried blood spots using LC-MS/MS. Prostaglandins Leukot Essent Fatty Acids 125: 1-7.

Hewawasam E, Liu G, Jeffery DW, Muhlhausler BS, Gibson RA. 2018. A stable method for routine analysis of oxylipins from dried blood spots using ultra-high performance liquid chromatographytandem mass spectrometry. Prostaglandins Leukot Essent Fatty Acids 137: 12-18.

Liu G, Muhlhausler BS, Gibson RA. 2014. A method for long term stabilisation of long chain polyunsaturated fatty acids in dried blood spots and its clinical application. Prostaglandins Leukot Essent Fatty Acids 91: 251-60.

Ma P, Han L, Lv Z, et al. 2016. In-hospital free fatty acids levels predict the severity of myocardial ischemia of acute coronary syndrome. BMC Cardiovasc Disord 16: 29.
Makrides M, Neumann M, Simmer K, Pater J, Gibson R. 1995. Are long-chain polyunsaturated fatty acids essential nutrients in infancy? Lancet 345: 1463-8.

Makrides M, Gould JF, Gawlik NR, et al. 2014. Four-year follow-up of children born to women in a randomized trial of prenatal DHA supplementation. JAMA 311: 1802-4.

Makrides M, Best K, Yelland L, et al. 2019a. A Randomized trial of prenatal n-3 fatty acid supplementation and preterm delivery. $N$ Engl J Med 381: 1035-45.

Makrides M, Best K, Yelland L, et al. 2019b. A randomized trial of prenatal n-3 fatty acid supplementation and preterm delivery. New Engl J Med 381: 1035-45.

Marangoni F, Colombo C, Galli C. 2004. A method for the direct evaluation of the fatty acid status in a drop of blood from a fingertip in humans: Applicability to nutritional and epidemiological studies. Anal Biochem 326: 267-72.

Marangoni F, Colombo C, Martiello A, Negri E, Galli C. 2007. The fatty acid profiles in a drop of blood from a fingertip correlate with physiological, dietary and lifestyle parameters in volunteers. Prostaglandins Leukot Essent Fatty Acids 76: 87-92.

Marc I, Piedboeuf B, Lacaze-Masmonteil T, et al. 2020. Effect of maternal docosahexaenoic acid supplementation on bronchopulmonary dysplasia-free survival in breastfed preterm infants: A randomized clinical trial. JAMA 324: 157-67.

Neuringer M, Connor WE, Van Petten C, Barstad L. 1984. Dietary omega-3 fatty acid deficiency and visual loss in infant rhesus monkeys. J Clin Invest 73: 272-6.

Plourde M, Cunnane SC. 2007. Extremely limited synthesis of long chain polyunsaturates in adults: implications for their dietary essentiality and use as supplements. Appl Physiol Nutr Metab 32: 619-34.

Rodriguez-Carrio J, Alperi-Lopez M, Lopez P, Ballina-Garcia FJ, Suarez A. 2016. Non-esterified fatty acids profiling in rheumatoid arthritis: Associations with clinical features and Th1 response. PLoS One 11: e0159573.

Simmonds LA, Sullivan TR, Skubisz M, et al. 2020. Omega-3 fatty acid supplementation in pregnancy-baseline omega-3 status and early preterm birth: Exploratory analysis of a randomised controlled trial. BJOG 127: 975-81.

Wheeler TG, Benolken RM, Anderson RE. 1975. Visual membranes: Specificity of fatty acid precursors for the electrical response to illumination. Science 188: 1312-4.

Wikipedia Contributors, The Free Encyclopedia. 2021. Michel Eugène Chevreul. Wikipedia. https://en.wikipedia.org/w/index.php?title= Michel_Eug\%C3\%A8ne_Chevreul\&oldid=1020260209.

Cite this article as: Gibson R. 2021. Old and new adventures with fatty acids and their oxylipins: The road towards personalised clinical nutrition. OCL 28: 49. 